\title{
7. Conducted forms of postgraduate training in emergency medicine of the staff of EMCC in Bulgaria. A retrospective 20 year study
}

\author{
Diana A. Dimitrova, PhD' \\ ${ }^{1}$ Department of Preventive Medicine, FPH, MU-Sofia, Sofia, Bulgaria
}

Continuing training, postgraduate courses as group or as individual training, drills, workshops are extremely important for the medical and paramedical staff (ambulance drivers) at the Emergency Medical Care Center (EMCC) in Bulgaria. This provide reliability and a high level of response in emergencies, disasters, accidents and catastrophes. The continuity of the training processes as Conducted forms of postgraduate training in emergency medicine of the staff of EMCC in Bulgaria guarantees high professionalism both within the national security of the country and for cross-border cooperation (1-5).

Purpose. The purpose of the study is to investigate the conducted forms of post-graduate emergency medicine training of the personnel of the Center for Emergency Medical Care (EMCC) in Bulgaria.

Materials and methods. An epidemiological study of staff of EMCC Blagoevgrad about forms of training of staff in 2014 was conducted. The field study is exhaustive. Data is processed with SPSS19 and stored electronically. A database of the Ministry of Health has also been used for a period of 20 years.

Results. In the period 1999 - 2001 systematic training of the doctors (physicians, and surgeons), the senior and middle medical staff from EMCC in Bulgaria was implemented. Funding is provided under the Loan Agreement with the World Bank. - Project "PHARE" The number of trained people during the period is 4548. Of these, doctors - 1330, other medical staff - 2099 and ambulance drivers - 1085. (1-4) Since 2001, sporadic staff training has been performed within specialized courses, with training being an exception rather than systemic activity - 326 members of EMCC-Blagoevgrad have been answered so. In the period 2012-2014, the first post-2001 systemic training of the EMCC staff was presented on the territory of the country. Funding is provided under the Operational Program "Human Resources Development" within the framework of the "Practical Introduction to the Treatment of Emergency Situations" Project PULSS The project fulfilled over $100 \%$ of the set indicators. The number of people trained by 2014 is:

1. 5580, of which doctors - 1339, medical specialists 2219 , drivers 2022 - from emergency medical (EM) centers; and

2. 442 physicians and medical specialists from 33 emergency room as part of Multi-profile Hospital for Active Treatment (MHAT) in Bulgaria.

Handbook - pocket format $-8,000$ copies

Graphically made and printed $-8,000$ copies
The following activities have been successfully completed $(1-3,5)$ :
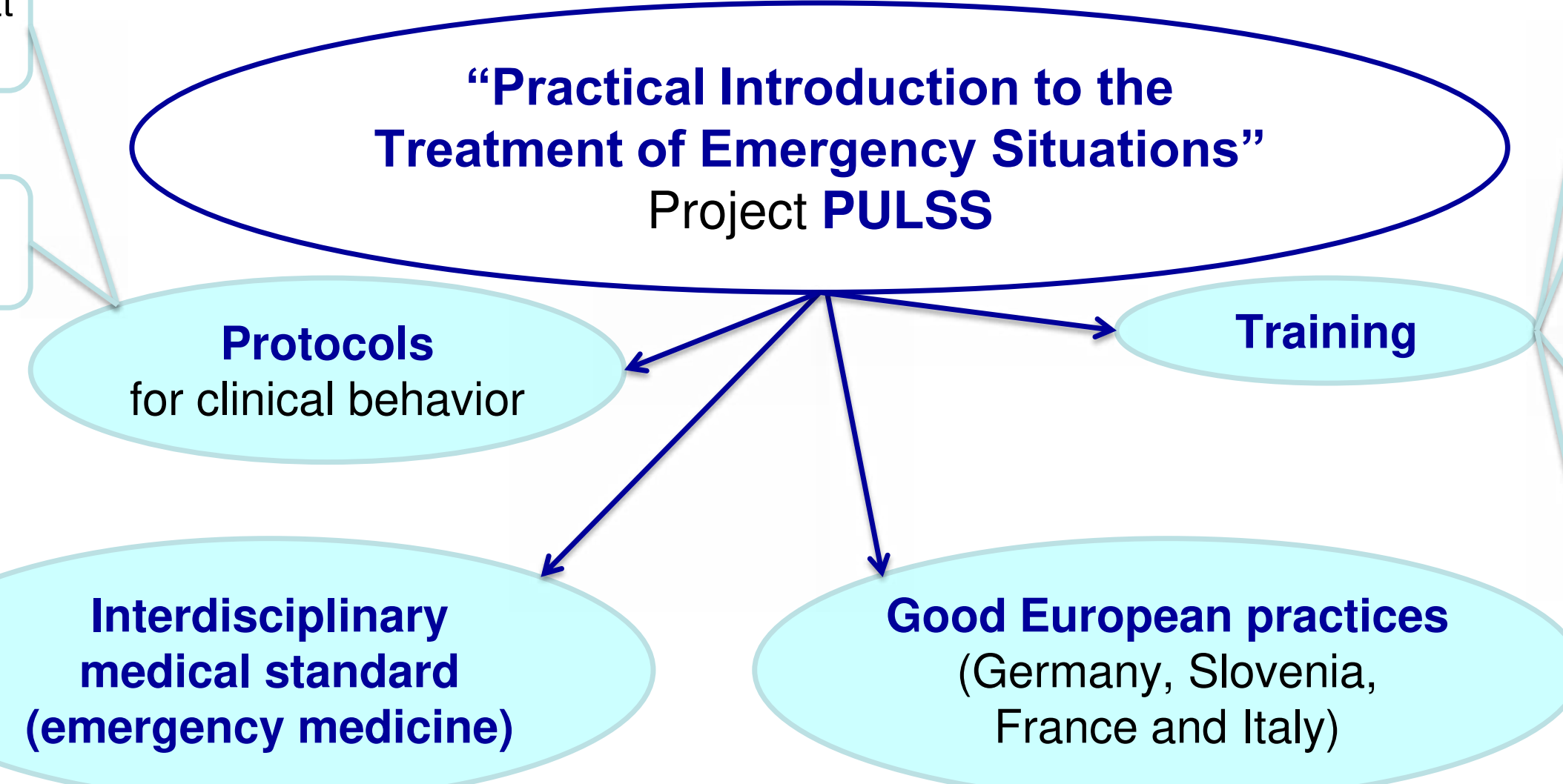

Analyzes and databases (to support training)

A contemporary training program

A website for advanced training

Hardware and software

(for upgrading training) high-tech training dummies

\begin{abstract}
Conclusions The training of EMCC staff is a guarantor of quality in the provision of emergency aid. For the surveyed period only two systemic training of the personnel of EMCC in Bulgaria were organised. With recommendations from the epidemiological survey of 2014, modernization measures have been taken. The guideline is to master techniques for rendering emergency help during air ambulance transport. A training program for telemedicine personnel is foreseen. $(1,3)$
\end{abstract}

\section{Sources:}

1. Dimitrova D., Medical provision of population during earthquakes - readiness of Emergency medical care center in Blagoevgrad region., MU-Sofia, 2015 - PhD thesis

2. Dimitrova D., Mechanism for effective functioning of the working shift in EMCC, SWU-Blagoevgrad, 2001 - Scientific master thesis

3. Dimitrova D., Pre-hospital medical care during disasters - readiness of emergency medical care centre in Bulgaria., in: Guideline of preventive medicine, Pub. Science and art, Sofia., 2017

4.Briefing N33: The PHARE programme and the enlargement of the European Union, 2004/016-. 919.01.01 BG04

5.Project BG051PO001-6.02.02 "PULSS - Practical Introduction to Emergency Treatment“http://www.mh.government.bg/bg
Key words: postgraduate studies, EMCC staff, Emergency Medicine, Bulgaria

European Resuscitation Council Congress, 19-21 September 2019, Ljubljana 